\title{
NKCC1 downregulation induces hyperpolarizing shift of GABA responsiveness at near term fetal stages in rat cultured dorsal root ganglion neurons
}

\author{
Joelle N Chabwine ${ }^{1,2^{*}}$, Karel Talavera ${ }^{3}$, Ludo Van Den Bosch ${ }^{4,5}$ and Geert Callewaert ${ }^{1}$
}

\begin{abstract}
Background: $G_{A B A}$ receptor-mediated neurotransmission is greatly influenced by cation-chloride cotransporter activity during developmental stages. In embryonic neurons $\mathrm{Na}-\mathrm{K}-2 \mathrm{Cl}$ (NKCC1) cotransporters mediate active chloride uptake, thus increasing the intracellular chloride concentration associated with GABA-induced depolarization. At fetal stages near term, oxytocin-induced NKCC1 downregulation has been implicated in the developmental shift from depolarizing to hyperpolarizing GABA action. Mature dorsal root ganglion neurons (DRGN), however, express high NKCC1 levels and maintain high intracellular chloride levels with consequent GABA-induced depolarization.
\end{abstract}

Results: Gramicidin-perforated patch-clamp recordings were used to assess the developmental change in chloride homeostasis in rat cultured small DRGN at the embryonic day 16 (E16) and 19 (E19). The results were compared to data previously obtained in fetal DRGN at E14 and in mature cells. A significant NKCC1 downregulation, leading to reduction in excitatory GABAergic transmission, was observed at E16 and E19.

Conclusion: These results indicate that NKCC1 activity transiently decreases in DRGN at fetal stages near term. This developmental shift in GABAergic transmission may contribute to fetal analgesia and neuroprotection at birth.

Keywords: Dorsal root ganglion neurons, GABA, Intracellular chloride, NKCC1, Bumetanide, Oxytocin, Fetal analgesia

\section{Background}

Cation-chloride cotransporters largely determine the action of GABA during neurogenesis [1-5]. In immature neurons, $\mathrm{Na}-\mathrm{K}-2 \mathrm{Cl}(\mathrm{NKCC} 1)$ mediates active $\mathrm{Cl}^{-}$ uptake, promoting depolarizing GABA action, whereas in adult neurons the $\mathrm{Cl}^{-}$-extruding $\mathrm{KCC} 2$ is generally considered to be involved in generating the hyperpolarizing effect of GABA. Mature dorsal root ganglion neurons (DRGN), however, express high NKCC1 levels and maintain high intracellular $\mathrm{Cl}^{-}$concentration $\left(\left[\mathrm{Cl}^{-}\right]_{\mathrm{i}}\right)$ with resulting GABA-induced depolarization [2, 6, 7].

\footnotetext{
*Correspondence: jo.nsimy@gmail.com

2 Present Address: Neurology Unit, Department of Medicine, Faculty of Sciences, University of Fribourg, Chemin du Musée, 5, Fribourg 1700, Switzerland

Full list of author information is available at the end of the article
}

This property is crucial for presynaptic inhibition of spinal sensory feedback $[2,7-11]$.

A NKCC1 downregulation has been observed around birth in different neuronal types of central nervous system (CNS) $[2,12,13]$ as a result of circulating maternal oxytocin [14-16]. Previously, we showed that DRGN at embryonic day 14 (E14) displayed higher NKCC1 activity and higher intracellular $\left[\mathrm{Cl}^{-}\right]_{\mathrm{i}}$ levels than age-matched motor neurons (MN) [17]. Here, we investigated whether DRGN also display NKCC1 downregulation at fetal stages near term, before increasing again to high expression levels in adult stage $[18,19]$.

Our data show a marked decrease in DRGN $\left[\mathrm{Cl}^{-}\right]_{\mathrm{i}}$ at E16 and E19 compared to E14. Decreased activity of NKCC1 at E16 and E19 fully accounts for this reduction in $\left[\mathrm{Cl}^{-}\right]_{\mathrm{i}}$. A possible role for this transient shift in GABAergic responses in DRGN is discussed. 


\section{Results and discussion}

GABA-induced currents were measured in cultured E16 and E19 DRGN. The results were quantitatively compared to data previously obtained in DRGN at E14 [17].

Total membrane capacitance remained stable between E14 [17] and E16 at $24 \pm 2 \mathrm{pF}(\mathrm{n}=11, \mathrm{p}=0.43)$, and slightly increased to $30.7 \pm 2 \mathrm{pF}$ at E19 $(\mathrm{n}=12$, $\mathrm{p}=0.006$ ), indicating that most of the cells examined were small DRGN (capacitance $30 \leq \mathrm{pF}$ ) [11]. Based on $E_{G A B A},\left[\mathrm{Cl}^{-}\right]_{\mathrm{i}}$ markedly decreased from $44 \mathrm{mM}$ at E14 to 30 and $29 \mathrm{mM}$ at E16 and E19, respectively (Figure 1). In the presence of the selective NKCC1 blocker bumetanide $(10 \mu \mathrm{M}),\left[\mathrm{Cl}^{-}\right]_{\mathrm{i}}$ was significantly reduced to $\sim 20 \mathrm{mM}$ at all stages, indicating that NKCC1-dependent $\mathrm{Cl}^{-}$influx significantly dropped between E14 (57\%) and E16 (33\%), with no further decrease up to E19 (38\%).

Changes in NKCC1 regulation were further explored by studying $\left[\mathrm{Cl}^{-}\right]_{\mathrm{i}}$ recovery after $\mathrm{Cl}^{-}$load and $\mathrm{Cl}^{-}$depletion in DRGN at E19. Applying $1.5 \mathrm{mM}$ GABA for $5 \mathrm{~s}$ at a membrane potential of $+70 \mathrm{mV}$ consistently shifted the reversal potential in the positive direction, indicating an increase in $\left[\mathrm{Cl}^{-}\right]_{\mathrm{i}}$ from 33 to $43 \mathrm{mM}(\mathrm{n}=2)$. Similar results were previously obtained in E14 DRGN [17] $\left(\mathrm{p}=0.38\right.$ between respective increases in $\left.\left[\mathrm{Cl}^{-}\right]_{\mathrm{i}}\right)$. Following $\mathrm{Cl}^{-}$loading, recovery to basal $\left[\mathrm{Cl}^{-}\right]_{\mathrm{i}}$ levels followed a single exponential function with a time constant of $2.97 \pm 0.1 \mathrm{~min}(\mathrm{n}=5$, Figure $2 \mathrm{~b})$, which is not different from that previously recorded in E14 DRGN [17] (Figure 2a, $\mathrm{p}=0.44$ ). Applying $1.5 \mathrm{mM}$ GABA for $5 \mathrm{~s}$ at a membrane potential of $-100 \mathrm{mV}$ reduced $\left[\mathrm{Cl}^{-}\right]_{\mathrm{i}}$ by only $3 \mathrm{mM}$ [from 31 to $28 \mathrm{mM}(\mathrm{n}=3)$ ] whereas in

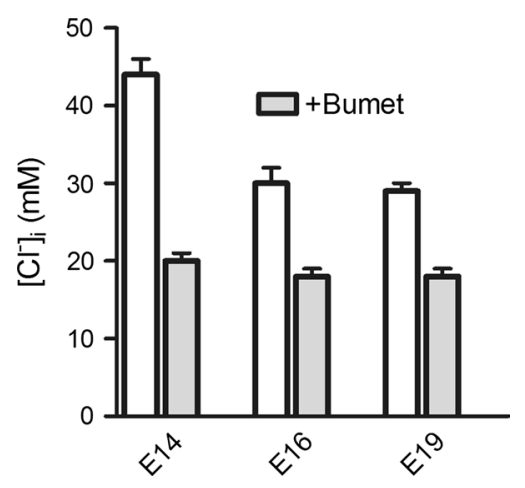

Figure 1 Intracellular $\left[\mathrm{Cl}^{-}\right]$and bumetanide-induced $\mathrm{Cl}^{-}$reduction in DRGN. The resting $\left[\mathrm{Cl}^{-}\right]_{\mathrm{i}}$ (open bars) dropped significantly between $\mathrm{E} 14(44 \pm 2 \mathrm{mM}, \mathrm{n}=71)$ and $\mathrm{E} 16(30 \pm 2 \mathrm{mM}, \mathrm{n}=11, \mathrm{p}=0.00003)$, with no further decrease at $\mathrm{E} 19(29 \pm 1 \mathrm{mM}, \mathrm{n}=13, \mathrm{p}=0.81)$. In the presence of $10 \mu \mathrm{M}$ bumetanide (+Bumet, grey bars), a specific blocker of $\mathrm{NKCC1},\left[\mathrm{Cl}^{-}\right]_{\mathrm{i}}$ was decreased to $20 \pm 1 \mathrm{mM}(n=6)$ at E14 and to $18 \pm 1 \mathrm{mM}(n=6)$ at E16 and E19. The bumetanide-insensitive component remained stable at all stages ( $p=0.73$ for E14 versus E16 and $p=0.46$ for E14 versus E19).
E14 DRGN, $\left[\mathrm{Cl}^{-}\right]_{\mathrm{i}}$ dropped by $8 \mathrm{mM}$. This difference in $\left[\mathrm{Cl}^{-}\right]_{\mathrm{i}}$ reduction between E14 and E19 DRGN during the depletion protocol was significant $(p=0.009)$. Following $\mathrm{Cl}^{-}$depletion, recovery to the resting $\left[\mathrm{Cl}^{-}\right]_{\mathrm{i}}$ level was also significantly slower in E19 DRGN (time constant of $1.64 \pm 0.1 \mathrm{~min}, \mathrm{n}=5$ ) (Figure 2d) than in E14 DRGN (time constant of $0.9 \pm 0.1 \mathrm{~min})(\mathrm{p}=0.002$, Figure 2c). Together, these data strongly suggest that NKCC1-related $\mathrm{Cl}^{-}$fluxes markedly decreased in small DRGN after day E14.

It was previously shown that mature and embryonic DRGN sustain high $\left[\mathrm{Cl}^{-}\right]_{\mathrm{i}}$ owing to high NKCC1 expression $[2,11,18]$. Here, we show that embryonic DRGN undergo a significant downregulation of NKCC1 between E14 and E16 (maintained through E19), which significantly affects $\mathrm{Cl}^{-}$homeostasis. The resulting overall decrease in $\left[\mathrm{Cl}^{-}\right]_{\mathrm{i}}$ limits the depolarizing action of GABA. Notably, $\left[\mathrm{Cl}^{-}\right]_{\mathrm{i}}$ at E14 is comparable to the level reported in the postnatal period (P0-P21) $[19,20]$ and possibly in adult DRGN [18] implying that the observed drop in $\left[\mathrm{Cl}^{-}\right]_{\mathrm{i}}$ between day E16 and E19 is only a transient phenomenon. The underlying mechanism most probably involves decreased NKCC1 activity rather than lower expression level [14, 20-22].

\section{Conclusion}

These data accord with previous observations in other CNS neuronal types showing that NKCC1 activity is decreased as a result of increasing levels of circulating maternal oxytocin at near term. However, in contrast to other neuronal types, the activity-dependent downregulation of NKCC1 in DRGN is not permanent but only transient. Since we predominantly studied small DRGN (capacitances $\leq 30 \mathrm{pF}$ ) [11] in which GABA-induced depolarization is essential for sensory perception [2, 7-9, $11]$, we suggest that the transient GABAergic hyperpolarizing shift observed between E16 and E19 reflects oxytocin-induced fetal adaptation to delivery [14, 16], contributes to fetal analgesia and protects the fetus against neuronal insult.

\section{Methods}

All experimental procedures were approved by the local Ethical Committee and were therefore performed in accordance with international ethical regulations. DRGN were derived from Wistar rat embryos at E16 and E19, and cultured as previously described [17]. Tissue samples were trypsinized and triturated and neurons were purified by centrifugation using a bovine serum albumin cushion and then plated on poly-L-ornithine and laminincoated glass coverslips. Neurons were used between 3 and 6 days after plating. GABA-induced currents $\left(I_{G A B A}\right)$ were recorded under voltage-clamp conditions using 

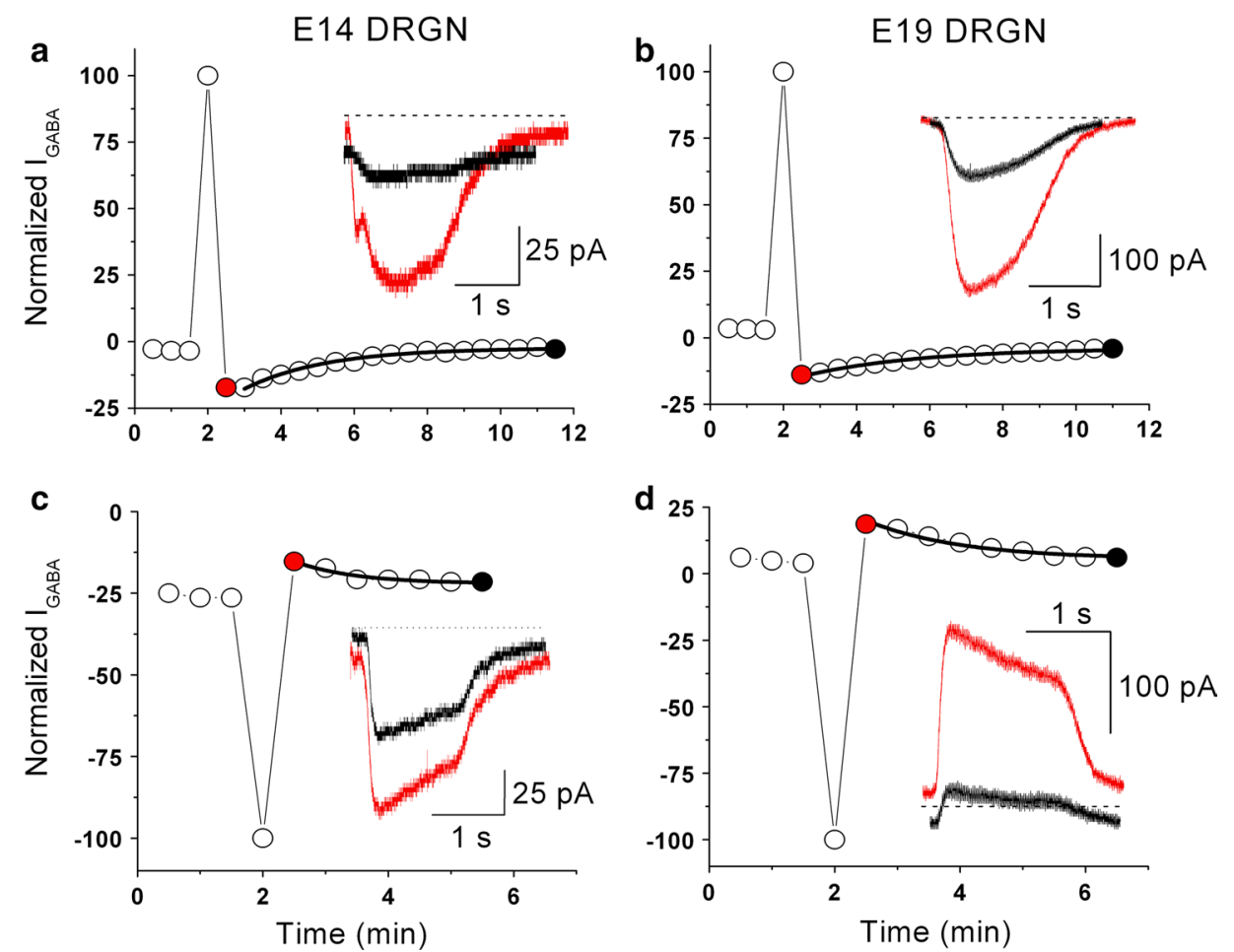

Figure $2 \mathrm{Cl}^{-}$load $(\mathbf{a}, \mathbf{b})$ and depletion (c, d) in DRGN at fetal stages E14 and E19. DRGN were held at $-40 \mathrm{mV}$ and $500 \mu \mathrm{M}$ GABA was applied for $1 \mathrm{~s}$ every $30 \mathrm{~s}$. $\mathrm{Cl}^{-}$load was induced by a $5 \mathrm{~s}$ GABA pulse $(1.5 \mathrm{mM})$ during a depolarizing step to $+70 \mathrm{mV}$ while $\mathrm{Cl}^{-}$depletion was induced by applying the same pulse of GABA during a hyperpolarizing step to $-100 \mathrm{mV}$. GABA $_{\text {was }}$ warmalized to the value obtained during the voltage step to +70 or $-100 \mathrm{mV}$. The continuous lines show the fit of data during recovery using a single exponential function. Recovery time constants after $\mathrm{Cl}^{-}$load were 2.23 and 3.19 min at E14 (a) and E19 (b), respectively. Recovery time constants after $\mathrm{Cl}^{-}$depletion amounted to 0.79 and 1.5 min at E14 (c) and E19 (d), respectively. Insets I IABA recordings at times indicated by matched colors.

gramicidin-perforated patches [17] $(75 \mu \mathrm{g} / \mathrm{ml}$, Fluka). The pipette solution contained (in $\mathrm{mM}$ ): $\mathrm{CsCl} 125, \mathrm{MgCl}_{2}$ 1.2, HEPES 10, $\mathrm{Na}_{2}$ ATP 2 and EGTA 1 and the $\mathrm{pH}$ was adjusted to 7.3 with $\mathrm{CsOH}$. Patch pipettes (3-5 $\mathrm{M} \Omega$ resistance) were briefly dipped in gramicidin-free pipette solution and back-filled with internal solution. After seal formation and stable access resistance $\leq 30 \mathrm{M} \Omega$, GABA was locally applied using a fast perfusion system. The external solution contained (in $\mathrm{mM}$ ): $\mathrm{NaCl} 150, \mathrm{KCl} 6$, $\mathrm{MgCl}_{2} 1, \mathrm{CaCl}_{2} 3$, HEPES 10 and glucose 10, $\mathrm{pH}$ adjusted to 7.3 with $\mathrm{NaOH}$. $500 \mathrm{nM}$ TTX (tetrodotoxin, Alomone labs) and $100 \mu \mathrm{M} \mathrm{Cd}^{2+}$ were added to block voltagegated $\mathrm{Na}^{+}$and $\mathrm{Ca}^{2+}$ channels, respectively. Total external $\left[\mathrm{Cl}^{-}\right]$amounted to $164 \mathrm{mM}$. Bumetanide $(10 \mu \mathrm{M})$ was used to specifically block NKCC1 cotransporters $[4,6]$.

The reversal potential for $I_{G A B A},\left(E_{G A B A}\right)$ determined with brief voltage ramps during GABA application, was used to estimate intracellular $\mathrm{Cl}^{-}$levels [17]. Intracellular $\left[\mathrm{Cl}^{-}\right]$depletion or loading was achieved by applying a $5 \mathrm{~s}$ pulse of GABA $(1.5 \mathrm{mM})$ during a voltage step from the holding potential $(-40 \mathrm{mV})$ to $-100 \mathrm{mV}$ or to $+70 \mathrm{mV}$, respectively [12]. After depletion or loading, $\left[\mathrm{Cl}^{-}\right]$recovery was monitored by applying successive $1 \mathrm{~s}$-GABA pulses of $500 \mu \mathrm{M}$ every 30 s. [17]. All data are shown as mean \pm SEM. Statistically significant differences were evaluated with unpaired Student $t$ test $(\mathrm{p}<0.05)$.

\section{Abbreviations}

$\left[\mathrm{Cl}^{-}\right]_{\text {; }}$ intracellular chloride concentration; CNS: central nervous system; DRGN: dorsal root ganglion neuron; $E_{G A B A}$ : reversal potential for $I_{G A B A}: E G T A$ : ethylene glycol tetraacetic acid; E14: embryonic day 14; E16: embryonic day 16; E19: embryonic day 19; GABA: gamma amino butyric acid; HEPES: 4-(2-Hydroxyethyl)piperazine-1-ethanesulfonic acid; $I_{G A B A}$ : GABA-induced current; KCC2: potassium-chloride $(\mathrm{K}-\mathrm{Cl})$ cotransporter 2; $\mathrm{MN}$ : motor neuron; NKCC1: sodium-potassium-chloride ( $\mathrm{Na}-\mathrm{K}-2 \mathrm{Cl}$ ) cotransporter 1; P0: post-natal day 0; P21: post-natal day 21; TTX: tetrodotoxin.

\section{Authors' contributions}

JNC designed the study, carried all experiments, analyzed data, drafted and revised the manuscript. KT significantly contributed to the conception and the design of the study, to data analysis and to the revision of the manuscript. LVDB contributed to data acquisition, data analysis and manuscript revision. GC supervised the whole study, significantly contributed to its conception and experimental design, to data acquisition and analysis, and to manuscript revision. All authors read and approved the final manuscript. 


\section{Author details}

${ }^{1}$ Department of Cellular and Molecular Medicine, Katholieke Universiteit Leuven (KU Leuven), Louvain, Belgium. ${ }^{2}$ Present Address: Neurology Unit, Department of Medicine, Faculty of Sciences, University of Fribourg, Chemin du Musée, 5, Fribourg 1700, Switzerland. ${ }^{3}$ Laboratory of Ion Channel Research and TRP Channel Research Platform (TRPLe), Department of Cellular and Molecular Medicine, KU Leuven, Louvain, Belgium. ${ }^{4}$ Laboratory of Neurobiology, Experimental Neurology and Leuven Research Institute for Neuroscience and Disease (LIND), KU Leuven, Louvain, Belgium. ${ }^{5}$ VIB, Vesalius Research Center, KU Leuven, Louvain, Belgium.

\section{Acknowledgements}

Research was funded by the European Research Council under the European's Seventh Framework Programme (FP7/2007-2013)/ ERC Grant agreement no 340429, by the Interuniversity Attraction Poles Programme P7/16 initiated by the Belgian Science Policy Office and by the Research Council of the KU Leuven (EF/95/010 and PF-TRPLe).

\section{Compliance with ethical guidelines}

\section{Competing interests}

The authors declare that they have no competing interests.

Received: 19 March 2015 Accepted: 8 July 2015

Published online: 14 July 2015

\section{References}

1. Ben-AriY (2002) Excitatory actions of GABA during development: the nature of the nurture. Nat Rev Neurosci 3:728-739

2. Delpire E (2000) Cation-chloride cotransporters in neuronal communication. News Physiol Sci 15:309-312

3. Mercado A, Mount DB, Gamba G (2004) Electroneutral cation-chloride cotransporters in the central nervous system. Neurochem Res 29:17-25

4. Russell JM (2000) Sodium-potassium-chloride cotransport. Physiol Rev 80:211-276

5. Rivera C, Voipio J, Payne JA, Ruusuvuori E, Lahtinen H, Lamsa K et al (1999) The $\mathrm{K}^{+} / \mathrm{Cl}^{-}$co-transporter $\mathrm{KCC} 2$ renders $\mathrm{GABA}$ hyperpolarizing during neuronal maturation. Nature 397:251-255

6. Sung KW, Kirby M, McDonald MP, Lovinger DM, Delpire E (2000) Abnormal GABA $A_{A}$ receptor-mediated currents in dorsal root ganglion neurons isolated from Na-K-2Cl cotransporter null mice. J Neurosci 20:7531-7538

7. Rudomin P, Schmidt RF (1999) Presynaptic inhibition in the vertebrate spinal cord revisited. Exp Brain Res 129:1-37
8. Willis WD Jr (1999) Dorsal root potentials and dorsal root reflexes: a double-edged sword. Exp Brain Res 124:395-421

9. Price TJ, Hargreaves KM, Cervero F (2006) Protein expression and mRNA cellular distribution of the NKCC1 cotransporters in the dorsal root and trigeminal ganglia of the rat. Brain Res 1112:146-158

10. Laird JMA, Garcia-Nicas E, Delpire EJ, Cervero F (2004) Presynaptic inhibition and spinal pain processing in mice: a possible role of the NKCC1 cation-chloride co-transporter in hyperalgesia. Neurosci Lett 361:200-203

11. Devor M (1999) Unexplained peculiarities of the dorsal root ganglion. Pain 6:S27-S35

12. Dzhala VI, Talos DM, Sdrulla DA, Brumback AC, Mathews GC, Benke TA et al (2005) NKCC1 transporter facilitates seizures in the developing brain. Nat Med 11:1205-1213

13. Delpy A, Allain AE, Meyrand P, Branchereau P (2008) NKCC1 inactivation underlies embryonic development of chloride-mediated inhibition in mouse spinal motoneurons. J Physiol 586:1059-1075

14. Tyzio R, Cossart R, Khalilov I, Minlebaev M, Hubner AC, Represa A et al (2006) Maternal oxytocin triggers a transient inhibitory switch in GABA signaling in the foetal brain during delivery. Science 314:1788-1792

15. Ceanga M, Spataru A, Zagrean AM (2010) Oxytocin is neuroprotective against oxygen-glucose deprivation and reoxygenation in immature hippocampal cultures. Neurosci Lett 477:15-18

16. Ben Ari Y, Gaiarsa JL, Tyzio R, Khazipov R (2007) GABA: a pioneer transmitter that excites immature neurons and generates primitive oscillations. Physiol Rev 87:1215-1284

17. Chabwine JN, Talavera K, Verbeert L, Eggermont J, Vanderwinden J-M, De Smedt $\mathrm{H}$ et al (2009) Chloride handling in rat embryonic motor neurons and dorsal root ganglion neurons. FASEB J 23:1168-1176

18. Alvarez-Leefmans FJ, Gamino SM, Giraldez F, Noqueron I (1988) Intracellular chloride regulation in amphibian dorsal neurones studied with ion selective microelectrodes. J Physiol 406:225-246

19. Rhocha-Gonzalez HI, Mao S, Alvarez-Leefmans FJ (2008) Na+, K+, $2 \mathrm{Cl}$ - cotransport and intracellular chloride regulation in rat primary sensory neurons: thermodynamic and kinetic aspects. J Neurophysiol 100:169-184

20. Mao S, Garzon-Muvdi T, Di Fulvio M, Chen Y, Delpire E, Alvarez FJ et al (2012) Molecular and functional expression of cation-chloride cotransporters in dorsal root ganglion neurons during postnatal maturation. $J$ Neurophysiol 108:834-852

21. Li H, Tomberg J, Kaila K, Airaksinen MS, Rivera C (2002) Patterns of cation-chloride cotransporter expression during embryonic rodent CNS development. Eur J Neurosci 16:2358-2370

22. Wang C, Shimizu-Okabe C, Watanabe K, Okabe A, Matsuzaki H, Ogawa T et al (2002) Developmental changes in KCC1, KCC2 and NKCC1 mRNA expressions in the rat brain. Brain Res Dev Brain Res 139:59-66

\section{Submit your next manuscript to BioMed Central and take full advantage of:}

- Convenient online submission

- Thorough peer review

- No space constraints or color figure charges

- Immediate publication on acceptance

- Inclusion in PubMed, CAS, Scopus and Google Scholar

- Research which is freely available for redistribution

Submit your manuscript at www.biomedcentral.com/submit
C Biomed Central 